\title{
TOWARDS CREATIVE LEAN (CLEAN) CONSTRUCTION: FROM LEAN PRODUCTION TO LEAN CONSUMPTION
}

\author{
Vishal Singh ${ }^{1}$
}

\begin{abstract}
The current approaches in lean construction are primarily production oriented. More recently, there has been greater attention towards what we design, based on approaches such as Target Value Design. Despite these developments, the need for production is taken as the default starting point in the design explorations. On the other hand, new business models and approaches such as Space-As-A-Service may at times eliminate the need for any production at all, and yet deliver the desired functionalities and values to the target users and customers. Such solutions, based on principles of shared resources and sharing economy can be viewed as 'Lean consumption' models that eliminate waste in consumption patterns itself. Since such alternative approaches require divergent thinking, there is need to integrate creative design methodologies in lean construction practice. Therefore, this paper aims to initiate this discussion on Creative Lean (CLean) Construction, as a step from lean production to lean consumption.
\end{abstract}

\section{KEYWORDS}

Creative Lean Construction, Lean design management, Lean consumption, missed opportunity, disruption

\section{INTRODUCTION}

Together with digitalization, lean construction and management is one of the key goals driving the future of construction (Armstrong et al 2016, Agarwal et al 2016, WEF and BCG 2016). Nonetheless, the current discussions and approaches in lean construction are primarily production oriented, aiming to reduce waste in how we design, build, construct and manage built facilities (Koskela 2000). More recently, there has been greater attention towards what we design, based on approaches such as Target Value Design, which emphasize lifecycle value proposition and value analysis (Zimina et al 2012). Despite these developments, in general, the need for production is assumed, and that is taken as the default starting point in the design explorations. On the other hand, new

Assistant Professor, Department of Civil Engineering, Aalto University, Finland, +358504315667, Vishal.Singh@aalto.fi 
business models and service-oriented approaches such as Space-As- A-Service may sometimes altogether eliminate the need for any physical production at all, and yet deliver the desired functionalities and values to the target users and customers. For example, services such as Air BnB can in some instances eliminate the need for a new hotel because there might already be accommodation alternatives for visitors in a given locality (Zervas et al 2017). This not only changes the dynamics of the real estate business, but it also affects decisions pertaining to design and construction. Thus, solutions based on approaches such as shared resources and sharing economy may be termed as 'Lean consumption' approaches such that we eliminate waste in our consumption patterns itself. The proposed lean consumption view can also be seen as extending the 'waste in overproduction' concept to higher levels of abstraction, opening new opportunities in how we conceive what and how we design and use spaces and the built environment in the future. Given that the exploration of such alternative approaches requires divergent thinking, there is need to integrate creative design methodologies in lean construction. This paper aims to initiate this discussion on the Creative Lean (CLean) Construction, as a step from lean production to lean consumption.

The primary questions raised in this paper are: How do we build an understanding of lean consumption, and how is it going to be different and complementary to lean production? Are the established theories and methodologies in lean construction adequate to explain the scope of lean consumption or can we extend them building on theoretical models from cognitive design research? How does a lean consumption approach fit within the scope of lean construction? This paper takes the first steps towards building a theoretical and conceptual understanding of lean consumption in construction.

\section{METHODOLOGY}

This paper is based on theoretical arguments, reflective research (Fook 1996, Schön 1983) and thought experiments (Brown and Fehige 2017). Both reflective research and thought experiments are qualitative research methods suitable for abductive reasoning on topics where inductive and deductive reasoning is difficult, and where empirical data is either not available or not particularly useful.

Reflective practice is considered particularly useful as an iterative process in building what-if scenarios, where new solutions and problems emerge as the iteration progresses through multiple steps. Building such iterative scenarios can be part of thought experiments. As Brown and Fehige (2017) write about thought experiments, "...Historically their role is very close to the double one played by actual laboratory experiments and observations. First, thought experiments can disclose nature's failure to conform to a previously held set of expectations. Second, they can suggest particular ways in which both expectation and theory must henceforth be revised...”.

Therefore, we used thought experiments to assess whether the current discussion on lean construction meets the expectations, or whether we can identify gaps and theoretical lenses to revise the scope and objectives. 


\section{BACKGROUND}

\section{TRENDS IN LEAN CONSTRUCTION RESEARCH AND PRACTICE}

Some of the key concepts that have gained particular attention and traction in the lean construction research in recent years include:

Last Planner Systems (LPS) (Ballard 2000a) has been a popular lean method that emphasizes collaborative planning, weekly updates, feedbacks and revisions, with clear decision protocols has shown proven results. The delegation of responsibility and power of influencing the master plan to the "last planner", the people on the team responsible for making the final assignment of work to specific performers and ensuring that they have the materials, equipment, and information available to complete their assignments.

At the interface of BIM and Lean, there is increasing recognition of how BIM tools and processes can support several lean construction principles, including reduction in cycle times, increased flexibility, standardization, use of visual management, improving flow and value, and so on (Sacks et al 2010). While there is increasing role of technology in achieving lean objectives, there is also a greater realization that technology alone will not solve the problem, and the social and organizational aspects need to be improved in BIM processes and practices. The emergence of Integrated Project Delivery is one of the most significant contractual and collaborative practice to emerge at the interface of BIM and lean (Matthews and Howell 2005). The relational contracts, and shared responsibilities and rewards, mark a notable shift in how construction projects can be managed more efficiently.

Target Value Design (TVD): The emphasis on delivering value has always been a critical part of lean philosophy, but more recently the emphasis on identifying and targeting core customer value, taking the lifecycle perspective upfront in the design phase has grown significantly with the TVD approach (Zimina et al 2012). TVD relies on early and continuous engagement of customers and key stakeholders in the design process; close collaboration between all stakeholders, and; focusing on designing to a target value and estimate, rather than estimating the value after the design is done. TVD draws early attention towards the need for continuous improvement; expecting teams to deliver innovation that requires learning and re-planning, and; work with set-based design allowing multiple options to be retained in the design process.

TVD builds on the objectives laid out in the Lean Project Delivery Systems (LPDS) (Ballard 2000b, 2006, 2008), which emphasizes iterations and learning loops across the project lifecycle, including the need for attention towards project definition, purpose and use. LPDS reiterates the need for better articulation and mapping of ends, means and constraints in a project, consistent with the Theory of technical systems (Hubka and Eder 1988) and associated methodologies such as value analysis, function-means trees, etc.

Design management: The growing discussion on various aspects of design including early engagement of various stakeholders, TVD, collaborative and concurrent design, setbased design, etc is reflective of the recognition of the importance of design management (e.g. Koskela et al 1997). There is need to reduce waste in the design process, reduce rework, and focus on value added activities. Based on the review of design management 
literature in construction, Uusitalo et al (2017) identified the following key categories associated with lean design management (LDM):

- Social processes (LPS, Big Room, co-location, Integrated Concurrent Engineering, Collaborative Planning in Design)

- Methods (Level of Detail, Location-Based Design Management, TVD, Set-Based Design, Choosing By Advantages, Real-time cost estimation)

- Tools/ Technologies (Virtual Design and Construction, Design Structure Matrix (DSM), Dialogue Matrix, A3 Report, Scrum)

LDM is an emerging sub-research area, and together with greater industrialization, prefabrication and process improvements in the construction process, several other methods and approaches from engineering design research such as Design for Manufacturing and Assembly (DFMA), etc are increasingly being explored and discussed in the lean construction research. Therefore, it is timely to review the scope of current approaches to LDM in construction, identify the core assumptions and basis for LDM discussion, and ascertain areas where LDM can benefit from the prior research in complementary areas of design research (e.g. Gero 1990, Dorst and Cross 2001, Lawson 2005). Following are the notable points associated with LDM:

- As the name goes, LDM is about design management, with the focus on reducing waste in how design is managed. Thus, the focus is on the management of the design process, rather than the design process itself, where design process refers to the cognitive act of designing, generation of design and design alternatives. LDM discussions currently do not go deeper into questions such as how ideas or solutions are generated or how design alternatives are arrived at? Instead, it goes onto aspects such as how many ideas or solutions were generated, how many of those were detailed further, how the set of ideas were managed and retained until later phases, and so on. Thus, LDM and design management adopts an operational view of design, dealing with tangible, tractable, and observable tasks, while intangible, covert processes associated with thinking and reasoning are not adequately accounted for. Even the iterative design processes are described differently in the design management literature and the cognitive design literature, such that the iteration in design management is described in terms of Plan-DoCheck-Act (PDCA) cycle of tasks and activities (Ballard and Howell 1994), while the iterations in cognitive design literature is described in terms of cognitive processes such as the Exploration- Generation- Evaluation-Communication steps described by Cross and colleagues (Cross 1992, Dorst and Cross 2001) or the iterative Function-Behaviour- Structure (FBS) framework and situated FBS framework of Gero and colleagues (Gero 1990, Kenningiesser and Gero 2004).

- The distinction between operational and cognitive views of design process is not trivial, especially in terms of tractability of value added activities and the assessment of waste. Since operational view is tractable and more transparent, it lends itself more accessible for external assessment of productivity and waste. In 
contrast, the cognitive processes remain mostly opaque, and hence, difficult to track and identify productive and non-productive sessions. Nonetheless, cognitive processes are the basis of decision making, and hence, cannot be overlooked for the lack of adequate measures to track and assess productivity.

- Another notable difference in the cognitive view of design is the recognition of the co-evolution of problems and solutions. In the cognitive design process, problem formulation and reformulation are considered an integral part of design iterations (Schon 1983). The openness to reformulation of the problem lends cognitive view more conducive to radical and disruptive changes in the definition and formulation of the design problem, unlike the operational view which tends to constrain the scope to incremental changes.

- LDM and the design management discussion in lean construction is currently focused at the design of the artefact, that is, the design of the target built facility. Consequently, the methods and approaches are product and production oriented. In contrast, the cognitive design literature takes a wider view of design, including design of processes and organizations.

\section{DIGITALIZATION DRIVEN TRENDS IN BUILT ENVIRONMENT}

Digitalization is expected to bring about a paradigm shift in the built environment and the construction sector (Armstrong et al 2016, Agarwal et al 2016, WEF and BCG 2016). Several notable trends are emerging, both in terms of the production process as well as the consumption process. In the recent years, the scope of BIM has continued to grow across the project lifecycle (Yalcinkaya and Singh 2015). Technical advancements in diverse areas are being proactively introduced across several pilot projects with potential for radical changes across various traditional activities. Similarly, there is opportunity and discussion around intelligent products, wireless monitoring and other advancements, which have potential for transformative impact.

In general, several of these technologies are being explored on experimental basis, occasionally based on open-ended and unstructured brainstorming of potential use case scenarios. There is limited evidence on whether these experimentations follow a planned process or opportunistic shift and exploration in solution approach based on novel technical paradigms. If it is the latter, it raises the question whether these paradigm shifts can be explained adequately using any of the LDM methods or current theories in lean construction, or if we need to draw upon the theories and models from creative design methods to explain the novelty of explorations and paradigm shifts. For example, a single-family unit can be constructed using different production systems ranging from traditional and labour-intensive brick-mortar construction to fully automated contour printing process. Using lean principles and theories we can compare which of these processes is better, and how each of these processes can by themselves be improved further through continuous improvements. However, none of the lean methodologies adequately explain or support coming up with alternative production methods. That is, lean methodologies support requirement analysis, explain iterative processes, explain 
transformation, flow and value in the design process, but none of these methodologies adequately explain or support disruptive reformulation of the problems and solutions.

In contrast, the cognitive design models and methodologies are open to problem reformulation and expansion of the conceptual design space. The design cognition based models and methodologies can explain and support both incremental and radical solutions, including disruptive paradigm shifts. Several of the creative engineering design and ideation methodologies such as TRIZ (Theory of Inventive Problem Solving), morphological charts, 6-3-5 brainwriting, etc are aimed at expanding the design space, creating new opportunities and alternative solutions which can lead to incremental as well as radical improvements (e.g. Altshuller 1984, Savransky 2000). Therefore, it is timely to integrate some of the methodologies and insights from the cognitive design models into LDM to keep up with the wider disruptive trends emerging in the society.

\section{WIDER SOCIO-TECHNICAL TRENDS AND THE CONSTRUCTION SECTOR: EXPECTATIONS FROM DESIGN AND INNOVATION}

The current optimism and expectations for significant leap in productivity and quality in the future of construction is consistent with wider global trends, including rapid technical advancements across various digital technologies, recognition of aggravating megachallenges such as resource constraints and issues listed in sustainable development goals (UN 2015), and resulting changes in ways of working and operating at all levels. Following are some of the factors transforming societal expectations from the construction sector:

- With several technical advancements maturing at the same time, the visions towards industry 4.0, towards a highly connected, smart society, autonomous systems, mass customization, etc are beginning to take more realistic form. Given the expectations of the next major cycle of societal revolution, various aspects of construction sector are likely to be challenged. We are entering the phase of widespread ideation and experimentations. How do we account for these experimentations and opportunities in the lean methods in a methodical way?

- With greater technical maturity, several of the new tools and hardware have also become readily available and affordable for wider consumption. The scope for innovation and systemic disruptions is not only limited to established companies and firms, but small group of individuals have unprecedented opportunity to trigger such disruptions with innovative solutions. Thus, established companies can hardly afford to focus entirely on established methods and practices, and they need to be alert to potential opportunities and threats that can escalate and diffuse rapidly, even in sectors that have traditionally been slow to respond to societal changes.

- The greater connectivity to build peer to peer networks and distributed systems has also resulted in the decentralization and horizontal expansion of the supply chain. The distinction between who can produce, who can supply and who consumes is getting blurred. Anyone with skills and resources can offer their 
services through online marketplace, produce goods in remote locations through digital manufacturing, and deliver it to customers through a logistics company.

- The peer to peer network and online marketplaces have also contributed to the rapid rise in service-oriented thinking, disrupting several product based industries that are moving towards product service systems to remain competitive. This has also led to emergence of the shared economy paradigm that allows greater sharing of resources and changing consumption behavior. It provides the alternative to deliver customer value through realignment of existing resources, without the need for production of new products. AirBnB is one such example.

- With greater emphasis on sustainability goals, lifecycle considerations, as well as improved ability to track and monitor the lifecycle details of produced goods and services, there is greater social, economic as well as political pressure towards approaches such as sustainable consumption and circular economy.

- There is an explosion in organized entrepreneurial activities, and new business models are being explored (Lindgardt and Ayers 2014). Established business models, management theories, and best practices may not necessarily be useful in all cases. Creative explorations will be expected, while at the same time following lean theories and approaches. For instance, lean startup methodologies (Ries 2012) have evolved emphasizing the need to focus on minimum viable products (MVP) and establish a build-measure- learn feedback loop.

Given these trends and rapidly changing technical as well as business landscape, established theories and best practices may need a closer inspection to plug the conceptual and theoretical gaps. The next section makes conceptual and theoretical propositions for further research and development of lean theories and methodologies.

\section{CONCEPTUAL AND THEORETICAL PROPOSITIONS FOR FUTURE RESEARCH AND DEVELOPMENT}

\section{LEAN PRODUCTION TO LEAN CONSUMPTION}

The lean construction methods and theories need to expand beyond lean production models to include lean consumption models. With the changing supplier-consumer relationship, greater emphasis on service oriented thinking, emergence of shared economy and similar approaches to resource realignment and reuse, there is opportunity to respond to as well as change consumption patterns and consumption behavior, while still delivering customer value. However, that would need a change in the mindset of traditional production- based sectors to acknowledge and embrace these possibilities, and identify these changes as business opportunities rather than threats.

In addition, there is need to develop the concept of lean consumption further to distinguish it from the concept of sustainable consumption, which primarily focuses on lifecycle management and circular economy. Similarly, such an approach can draw upon several complementary themes such as 'adaptable use' or design for adaptability (Beadle et al 2008), sharing in design (Chakrabarti2001, Chakrabarti and Singh 2007), etc. While 
the sustainable consumption objectives should be included in the lean consumption approach, it is argued that the scope of lean consumption can be broader, applicable at various levels of details and from individual tasks to industry level activities and processes.

\section{LDM TO LEAN DESIGN MANAGEMENT AND DESIGN PROCESSES (LDM-DP)}

There is a need to distinguish between design management, design methodology, and design thinking (Gerbov et al 2017). While design management adopts operational view of design, design methodology and design thinking focus on the cognitive view of design. Though operational and cognitive decision making are related, the current scope of LDM is limited to the operational aspects, giving only partial opportunity to realize and improve the potential of the design phase. Including the design methodology and design thinking in the lean design methodology should allow wider exploration, and greater exploitation of alternative opportunities that may arise from structured creative engineering methods.

\section{'MISSED OPPORTUNITY' AS ANOTHER CATEGORY OF WASTE}

The primary objectives of lean principles revolve around reduction and elimination of waste. The seven categories of waste in production (Ohno 1978) including overproduction, waiting, transportation, processing, inventory, movement, and making defective products, provide the foundation for the lean theory and methodologies. Besides these categories of waste that apply to any production system, additional waste categories have been proposed specifically based on insights from construction projects including 'making- do' (Koskela 2004), as well as 'Not listening' and 'Not speaking' that were proposed by Macomber and Howell (2004). These additional categories of waste are interesting because they extend beyond the strictly observable production related wastes to include more subjective aspects that are closer to decision processes. As Bertelsen (2004) notes, categories such as 'Not listening' and 'Not speaking' broadly refer to waste due to inaction. However, inaction is not merely limited to conversation and communication, but it can have a much wider implication, especially when we argue the need to extend the scope of lean construction from a production view to include the consumption perspective as well. Consequently, 'missed opportunity' is proposed as a category of waste that subsumes 'Not listening', 'Not speaking' or any other opportunity lost due to inaction or neglect.

While 'Missed opportunity' as a waste may be applicable to a wide range of production and operational scenarios, it is particularly relevant to lean construction, especially if we aim to achieve creative lean (Clean) construction proposed in this paper. This claim is based on the fact that unlike the traditional manufacturing industry that relies on fixed assembly lines, moulds, and production infrastructure that constrains the production system for years after setup, the project based nature of construction industry allows opportunity for construction firms and organizations to make changes in their production system both within and between construction projects. Thus, there is greater flexibility to spot or create opportunity for changes and improvements to be made, and to realize them in practice. 
Similarly, as emphasized in TVD as well as the models of design process, the iterations and feedback in the design process allow opportunities for reformulation of the problems and solutions, including radical shift in the approach. But are those opportunities for problem reformulation exploited or does the sunk-cost effect lead to wasted opportunities?

Such wasted opportunities can be found across several phases of the construction project, but they can be particularly detrimental in the early conceptual design phases or early planning phases when critical decisions are made. Since most construction projects are unique, and have unique design development requirements, 'missed opportunity' as a waste is particularly relevant to construction projects. In the end, the changing sociotechnical landscape offers a wide range of opportunities for improvement in the productivity of the construction sector, and the rate of adoption of new technologies and processes is contingent on whether we begin to see 'missed opportunities' as waste or not.

\section{CONCLUSIONS}

This paper argues the need to extend the scope of lean construction beyond lean production to include lean consumption. To achieve this objective creative engineering methodologies need to be included as part of the lean design methodologies. It is expected that incorporating creative design methodologies in the lean design methods will widen the exploration of potential opportunities to achieve lean objectives. 'Missing opportunities' is proposed as another category of waste, which is particularly relevant to capturing value from feedbacks and iterations. The discussions and arguments presented in this paper are aimed to initiate a discussion on lean consumption and creative lean methodologies.

\section{REFERENCES}

Agarwal, R, Chandrasekaran, S and Sridhar, M (2016) The digital future of construction, Voices, Global Infrastructure Initiative, McKinsey \& Company.

Altshuller, G. (1984). Creativity as an exact science. New York: Gordon \& Breach.

Armstrong, G and Gilge, C (2016) Building a technology advantage, Harnessing the potential of technology to improve the performance of major projects, Global Construction Survey 2016, KPMG International.

Ballard,G (2000a). The last planner system of production control. Doctoral dissertation, The University of Birmingham.

Ballard, G (2000b) Lean Project Delivery System. White Paper \#8, Lean Construction Institute, May 1, 6 pp.

Ballard, G. (2006) Rethinking Project Definition in terms of Target Costing. International Group for Lean Construction, Santiago, Chile, July, 2006, pp 77-90.

Ballard, G (2008) The lean project delivery system: an update. Lean Const. Jo. 5(1), 119.

Ballard, G and Howell, G (1994). Implementing Lean Construction: Improving Downstream Performance. Proc. 2nd IGLC, Chile, Santiago. 
Beadle, K., A. Gibb, S. Austin, A. Fuster, and P. Madden. 2008. Adaptable futures: Setting the agenda, I3CON International Conference, Loughborough, UK, 14-16 May Bertelsen, S (2004) Lean construction: where are we how to proceed? Lean Constr. Jo, 1, pp. 46-69.

Brown, JR and Fehige, Y (2017) Thought Experiments, The Stanford Encyclopedia of Philosophy, https://plato.stanford.edu/archives/sum2017/entries/thought-experiment/

Chakrabarti, A (2001) Sharing in design-categories, importance and issues, International Conference on Engineering Design, Glasgow, 21-23 August.

Chakrabarti, A and Singh, V (2007) A method for structure sharing to enhance resource effectiveness, Journal of Engineering Design 18(1), 73-91

Cross, N. (1982), Designerly ways of knowing, Design Studies 3 (4), pp. 221-227.

Dorst, K. and Cross, N. (2001). Creativity in design process: co-evolution of problemsolution. Design Studies, 22, 425-437.

Fook, J. (ed.) (1996) The Reflective Researcher: Social Workers' Theories of Practice Research. Sydney: Allen \& Unwin.

Gerbov, A, Singh, V and Herva, M. (2017) Challenges in applying design research studies to assess benefits of BIM in infrastructure projects Reflections from Finnish case studies, Engineering Construction and Architecture Management, 25 (1), pp.2-20.

Gero, J.S. (1990). Design prototypes: a knowledge representation schema for design, AI Magazine11(4), pp. 26-36.

Gero, J.S. and Kannengiesser, U. (2004). The situated function-behaviour-structure framework, Design Studies 25(4), pp. 373-391.

Hubka, V and Eder, WE (1988) Theory of Technical Systems, Springer-Verlag New York.

Koskela, L (2000): An exploration towards a production theory and its application to construction, Espoo, VTT Building Technology. 296 p. VTT Publications; 408.

Koskela, L. (2004): Making Do - the eighth category of waste. IGLC 12, Denmark, 2004

Koskela, L., Ballard, G., Tanhuanpää, V.-P. (1997) "Towards Lean Design Management." Proc. 5th Annual Conf. of IGLC, Gold Coast, Australia, pp. 1-12.

Lawson, B. (2005). How designers think: the design process demystified. Arch. Press.

Lindgardt, $\mathrm{Z}$ and Ayers, M (2014) Driving growth with business model innovation, $B C G$ Perspective, The Boston Consulting Group.

Macomber, H. and Howell, G.A.(2004): Two great wastes in organizations-A typology for addressing the concern for the underutilization of human potential. IGLC, Denmark

Matthews, O. and Howell G.A.(2005). Integrated Project Delivery An Example Of Relational Contracting. Lean Construction Journal, 2(1), April, 46-61.

Ohno, T. (1978): Toyota Production System, Beyond Large-Scale Production, Productivity Press, Cambridge Massachusetts.

Ries, E (2012). The Lean Startup Methodology.http://theleanstartup.com/ principles. 
Sacks, R., Koskela, L., Dave, B. and Owen, R. (2010) The Interaction of Lean and Building Information Modeling in Construction. J.of Const. Eng. and Manag.; 136(9), 968-980.

Savransky, S. D. (2000). Engineering of creativity, introduction to TRIZ methodology of inventive problem solving. CRC Press.

Schön, DA (1983) The reflective practitioner: How professionals think in action. New York: Basic Books.

UN General Assembly (2015). Transforming our world: the 2030 Agenda for Sustainable Development, 21 October 2015, A/RES/70/1.

Uusitalo, P, Olivieri, H, Seppanen, O, Pikas, E and Peltokorpi, A (2017) Review of Lean Design Management: Processes, methods and technologies, IGLC 2017, 571-578.

WEF and BCG (2016) Shaping the Future of Construction: A Breakthrough in Mindset and Technology, World Economic Forum, REF 220416

Yalcinkaya, M and Singh, V (2015) Patterns and trends in Building Information Modeling (BIM) research: A Latent Semantic Analysis. Automation in Construction 59, 68-80.

Zimina, D., Ballard, G. and Pasquire, C. (2012) Target value design: using collaboration and a lean approach to reduce construction cost. Const. Man. \& Econ.; 30(5), 383-398.

Zervas, G, Proserpio, D and Byers, JW(2017) The rise of the sharing economy: Estimating the impact of Airbnb on the hotel industry, J. of Marketing Re., 54(5) 687705. 